\title{
First report of Macrophomina pseudophaseolina infecting Lens culinaris
}

\author{
Mohamed El Amine Kouadri ${ }^{1}\left[\right.$. Souad Zaim ${ }^{1} \cdot$ Ahmed Amine Bekkar ${ }^{1}$
}

Received: 24 May 2021 / Accepted: 21 September 2021 / Published online: 24 September 2021

(c) Australasian Plant Pathology Society Inc. 2021

\begin{abstract}
In 2019 and 2020, charcoal rot symptoms were observed on lentil plants in fields located in the Northwest of Algeria (Mascara Tiaret and Relizane). Based on morphological and molecular identification using the internal transcribed spacer (ITS) sequence analyses, two representative isolates were identified as Macrophomina pseudophaseolina. Pathogenicity tests were performed and Koch's postulates were verified and fulfilled. To our knowledge, this is the first report of Macrophomina pseudophaseolina as the causal agent of charcoal rot of lentil in the world.
\end{abstract}

Keywords Lentil $\cdot$ Charcoal rot · Dry rot

Lentil (Lens culinaris) is one of the world's major pulse crops. In Algeria, it is one of the most consumed legumes after faba bean, chickpea and peas (Tabti et al. 2018). Lentil has the potential to fix nitrogen biologically. It has been included in crop rotations with cereals for effective cultural control of weeds, diseases and pests by breaking up their life cycles (Kumar et al. 2013). It is a potential adapted crop for dry areas in North Africa, South Asia, Sub-Saharan Africa, West Asia, and North Africa (Kumar et al. 2013).

Field surveys were conducted during 2019 and 2020 in the agricultural areas where lentil (Lens culinaris) is grown in three regions of Northwestern Algeria: Mascara, Tiaret and Relizane. In the field, the characteristic symptoms of charcoal rot were observed on infected plants which showed leaf chlorosis, brown discoloration of stem and roots that eventually dried causing premature death of seedlings. When plants were examined, black and abundant microsclerotia were observed at the stem base and on roots (Fig. 1). To isolate the causal agent, small pieces of symptomatic roots and stems were surface disinfected with $2 \% \mathrm{w} / \mathrm{v}$ sodium hypochlorite solution for $3 \mathrm{~min}$, after which they were washed with sterilized water 3 times. After subsequent drying between sterile filter papers they were cultured on potato

Mohamed El Amine Kouadri

melamine.kouadri@univ-mascara.dz

1 Laboratory of Research On Biological Systems and Geomatics (L.R.S.B.G), Department of Agronomy, Faculty of Life and Natural Sciences, University of Mustapha Stambouli Mascara, Mascara, Algeria dextrose agar (PDA) medium and incubated at $28^{\circ} \mathrm{C}$. All isolates were purified using the single hyphal tip method and observed with a light microscope for description of the morphology of the fungus. Pure cultures of fungal isolates were initially hyaline but turned to black over time. Masses of black, round to ovoid microsclerotia with an average size of $64 \mu \mathrm{m}$ formed on the culture 3 days after incubation. Pycnidiospores were produced in vitro by culturing the fungus on oatmeal agar medium and exposing the petri plates to UV light for 72h (Zhao et al. 2019). Pycnidiospores were numerous, small, single celled, hyaline and round or oval released from a rounded black pycnidium (Fig. 2). Morphological features of the isolates were typical of those of genus $\mathrm{Mac}$ rophomina (Nouri et al. 2020). Voucher specimens of the isolates M1 and M2 were deposited at the phytopathological herbarium of Ecole Nationale Supérieure Agronomique (ENSA, ex. INA, Algiers, Algeria) under accession numbers Herbier INA 0101 and 0100 respectively.

The identity of the isolates M1 and M2 was further confirmed by analysis of nucleotide sequences of the internal transcribed spacer (ITS) regions amplified using the primers ITS1/ITS4 (White et al. 1990). The nucleotide sequences obtained were submitted to GenBank with accession numbers MW422257 and MW420980. The BLASTn search with the ITS sequences of isolates M1 and M2 showed 100\% similarity with the sequence of Macrophomina pseudophaseolina ex-type strain CPC 21394 (KF951786).

Pathogenicity tests were conducted in triplicate three times using two methods. First, for the seed infestation method lentil seeds were soaked in microsclerotia 
Fig. 1 Charcoal rot symptoms observed on lentil plants (A) Stem base (B) Root
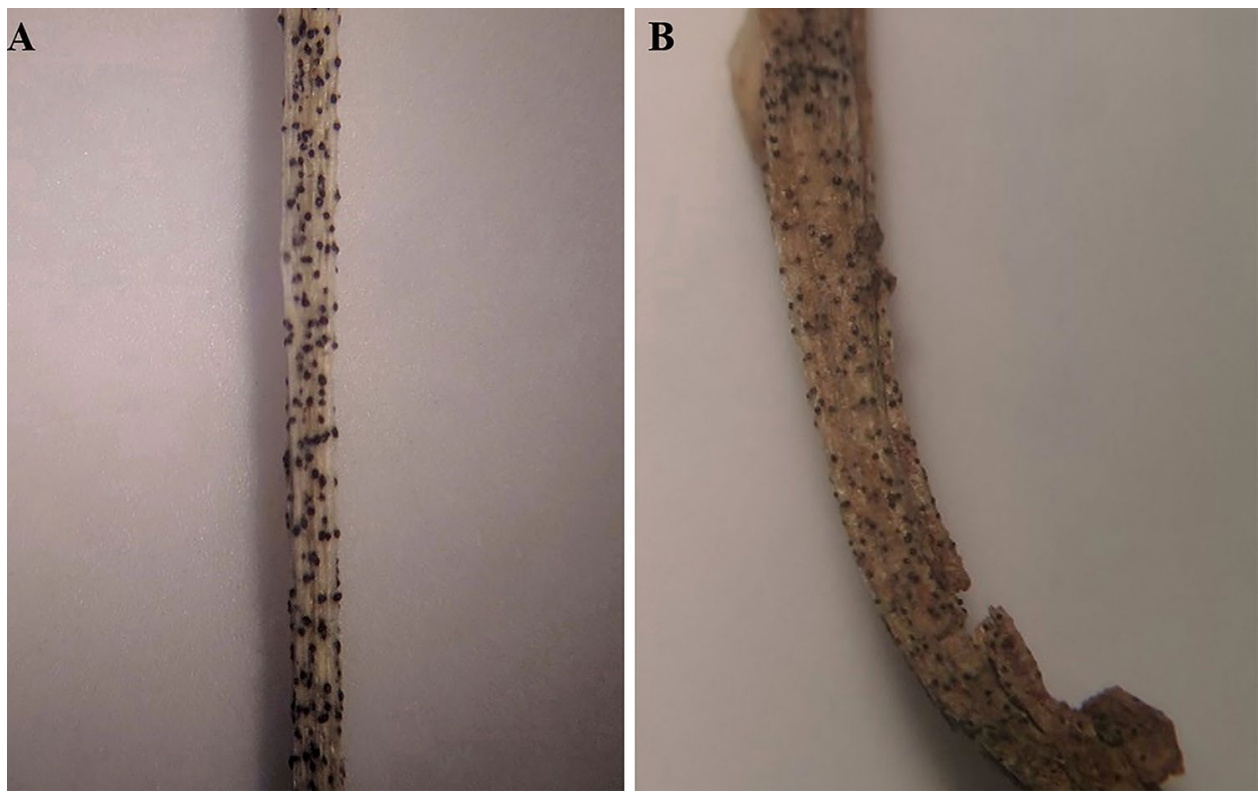

suspension $\left(10^{4} \mathrm{ml}^{-1}\right)$ for one hour and then transferred to $7 \mathrm{~cm}$ diameter pots containing sterile soil (Khanzada et al. 2012). Second, $60 \mathrm{ml}$ of microsclerotia suspension $\left(10^{4} \mathrm{ml}^{-1}\right)$ was poured into pots containing 10 days old lentil plants (Ullah et al. 2019). Control plants were treated with sterile distilled water. All plants were maintained in a greenhouse at $28^{\circ} \mathrm{C}$. Charcoal rot symptoms were observed on all inoculated plants, similar to those observed in the field, after 16 and 20 days respectively for the two methods, but no symptoms were seen on control plants. The infected plants were later collected and the pathogenic fungi were reisolated to fulfill Koch's postulates.
Fig. 2 Morphological characteristics of Macrophomina pseudophaseolina (A) Culture grown on potato dextrose agar (B) Microsclerotia (C) Pycnidiospores released from pycnidium (D) Pycnidiospores
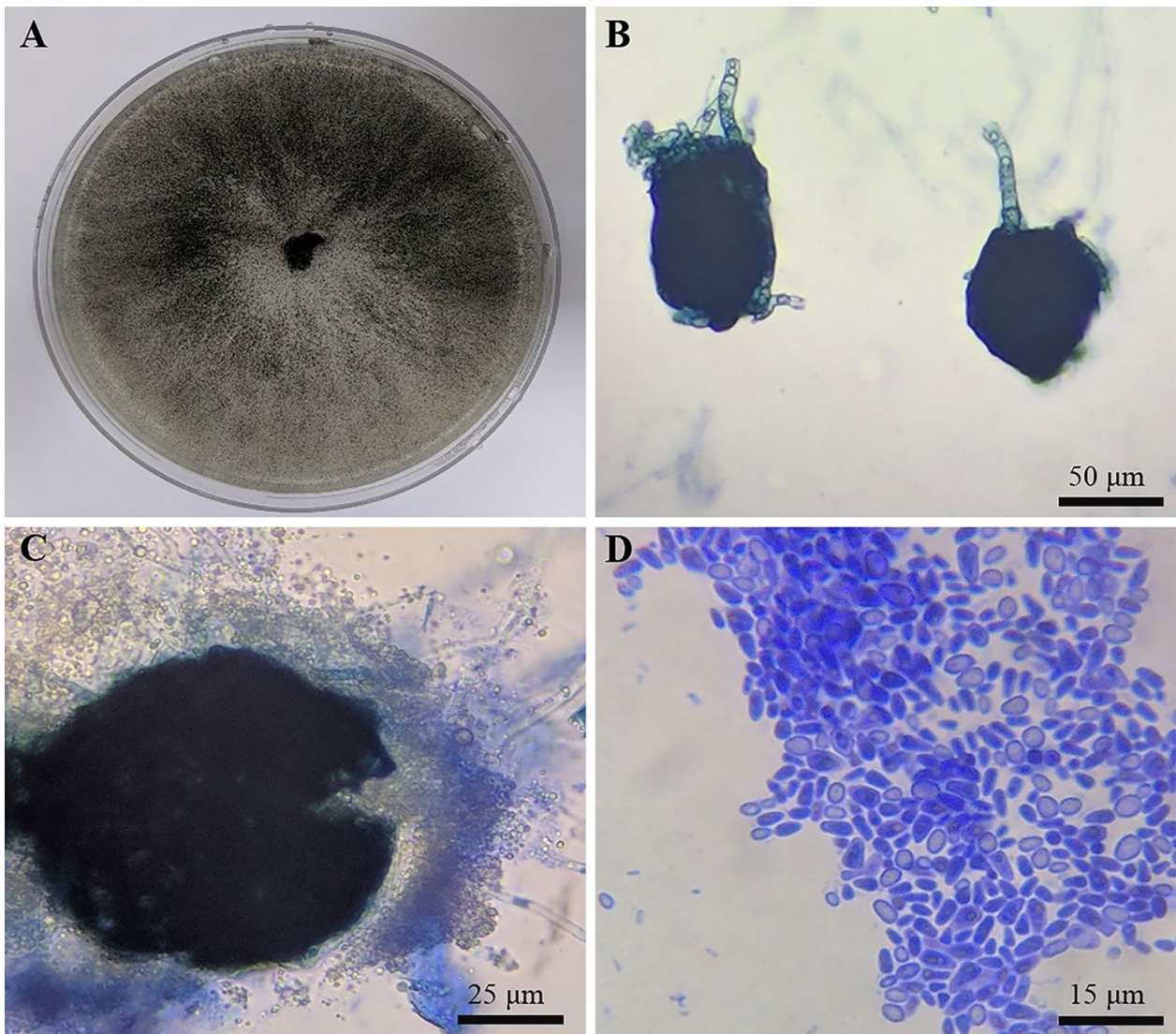
Macrophomina pseudophaseolina was first detected in Senegal (Sarr et al. 2014). It has been reported on 10 hosts, including two legumes; cowpea (Vigna unguiculata) and peanut (Arachis hypogaea) (Farr and Rossman 2021). In Algeria, this is the first report of M. pseudophaseolina on any crops. To our knowledge, this is the first report of M. pseudophaseolina causing charcoal rot on lentil plants in the world.

\section{References}

Farr DF, Rossman AY (2021) Fungal Databases, U.S. National Fungus Collections, ARS, USDA. https://nt.ars-grin.gov/fungaldatabases/ Retrieved May 22, 2021

Khanzada AM, Lodhi AM, Shah N, Maitlo SA (2012) Effect of different inoculation methods and inoculum levels of Macrophomina phaseolina on okra. Int J Phytopathol 1:01-05. https://doi.org/10. 33687/phytopath.001.01.0009

Kumar J, Srivastva E, Singh M (2013) Genetics of early growth vigour in lentil (Lens culinaris Medik.). J Genet 92:323-326. https://doi. org/10.1007/s12041-013-0257-8
Nouri MT, Lawrence DP, Kallsen CE, Trouillas FP (2020) Macrophomina crown and root rot of pistachio in California. Plants 9(2):134

Sarr MP, Ndiaye M, Groenewald JZ, and Crous P W (2014) Genetic diversity in Macrophomina phaseolina, the causal agent of charcoal rot. Phytopathol Medit 53(2):250-268. (53208)

Tabti DM, Laouar K. Rajendran S, Kumar A, Abdelguerfi A (2018) Identification of desirable mutants in quantitative traits of lentil at early $\left(\mathrm{M}_{2}\right)$ generation. J Environ Biol 39:137-142. https://doi. org/10.22438/jeb/39/2/MRN-476

Ullah N, Akhtar KP, Asghar MJ (2019) Abbas G (2019) First report of Macrophomina phaseolina causing dry root rot of lentil in Pakistan. J Plant Pathol 101:429. https://doi.org/10.1007/ s42161-018-00202-5

White TJ, Bruns TD, Lee S, Taylor J (1990) Amplification and direct sequencing of fungal ribosomal genes form phylogenetics. In: Innis MA, Gelfrand DH, Sninsky JJ, White TJ (eds) PCR protocols. Academic Press, San Diego, pp 315-322

Zhao X, Ni Y, Liu X, Zhao H, Wang J, Chen YC, Chen W, Liu H (2019) A simple and effective technique for production of pycnidia and pycnidiospores by Macrophomina phaseolina. Plant Dis 104:1183-1187. https://doi.org/10.1094/PDIS-08-19-1795-RE 